\title{
Índice de Estado Trófico de Lagos de Águas Claras Associados ao Baixo Rio Tapajós, Amazônia, Brasil
}

O Índice de Estado Trófico (IET) é uma ferramenta matemática capaz de classificar o grau de trofia de um corpo hídrico, avaliando a qualidade da água quanto às concentrações de clorofila-a e fósforo total, as quais são utilizadas para o cálculo do referido Índice. Os resultados correspondentes ao fósforo (P) devem ser entendidos como uma medida do potencial de eutrofização, já que este nutriente atua como o agente causador do processo. 0 objetivo do estudo foi identificar o estado trófico de lagos de águas claras, associado ao baixo rio Tapajós, utilizando o índice de estado trófico (IET). O estudo considerou uma abordagem espacia e temporal, no qual se realizaram duas amostragens em quatro lagos da margem direita do baixo rio Tapajós, sendo uma em outubro de 2016, na fase de águas baixas e outra em março de 2017 na fase de águas altas. Os parâmetros limnológicos foram analisados a partir de coletas de água na região Limnética, a 30cm abaixo da superfície, contra a água corrente. Os valores médios de índice de IET entre os lagos não possuem diferença significativa. Os valores de IETs foram discretamente mais elevados na fase de águas altas. Os valores ponderados de Fósforo Total e Clorofila-a indicaram que atualmente as águas dos Lagos Verde, Jacundá, Taparí e Juá se encontram no estado ultraoligotrófico. De acordo com a resolução 357/05, os quatro lagos apresentaram concentrações de Fósforo Total e Clorofila-a dentro da faixa permitida pela legislação e tendo pouca variação na distribuição destes.

\section{Index of Trophic State of Clear Water Lakes Associated with the Lower Tapajós River, Amazonia, Brazil}

\begin{abstract}
The Trophic State Index (TSI) is a mathematical tool capable of classifying the trophic status of a water body, evaluating the water quality with respect to chlorophylla and total phosphorus concentrations, which are used to evaluate the Index. The results corresponding to phosphorus (P) should be understood as a measure of the eutrophication potential, since this nutrient acts as the causative agent of this process. This study purpose was to identify the trophic status of clear water lakes, associated with the lower Tapajós-river, using the Trophic State Index (TSI). The study considered a spatial and temporal approach, in which two samplings were carried out in four lakes on the right bank of the lower Tapajós-river, one in October 2016 in the low water period, and another in March 2017 in the highwater period. The limnological parameters were analyzed from water sampling of the Limnetic region, $30 \mathrm{~cm}$ below the water surface, against the direction of water flow. The average values of (TSI) index among the lakes do not have a significant difference. Only between periods of low and high water, the latter having higher values. The weighted values of Total Phosphorusand Chlorophyll-a indicated that nowadays the waters of Lakes Verde, Jacundá, Taparí and Juá are in the ultraoligotrophic state. According to resolution 357/05, the four lakes had concentrations of Total Phosphorus and Chlorophyll-a within the range allowed by legislation, having little variation in the distribution of these.
\end{abstract}

Keywords: Trophic status index; Eutrophication; Water resources; Water quality.

Bianca Larissa de Mesquita Sousa (iD) Universidade Federal do Oeste do Pará, Brasil http://lattes.cnpq.br/2706289088522067 http://orcid.org/0000-0001-5064-2659 bianca.gestaoambiental@gmail.com

José Reinaldo Pacheco Peleja Universidade Federal do Oeste do Pará, Brasil http://lattes.cnpq.br/807578088761431 reinaldopeleja@yahoo.com.br

Brenda Leticia de Mesquita Sousa Universidade Federal do Oeste do Pará, Brasil http://lattes.cnpq.br/9942806970265780 leticiabrenda@hotmail.com

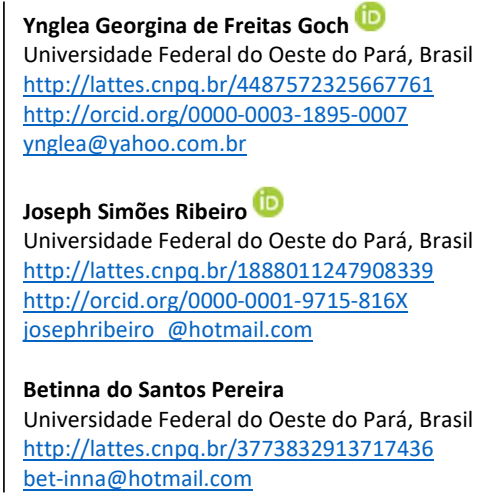

Flávia Cristina Carvalho de Lima Universidade Federal do Oeste do Pará, Brasi http://lattes.cnpq.br/6228881728501774 quimica flavia@yahoo.com.br

Edvaldo Junior de Souza Lemos Universidade Federal do Oeste do Pará, Brasil http://lattes.cnpq.br/2974368476892162 edvaldo lemos@yahoo.com.br

\section{Referencing this:}

SOUSA, B. L. M.; PELEJA, J. R. P.; SOUSA, B. L. M.; GOCH, Y. G. F.; RIBEIRO, J. S.; PEREIRA, B. S.; LIMA. F. C. C.; LEMOS, E. J. S.. Índice de Estado Trófico de Lagos de Águas Claras Associados ao Baixo Rio Tapajós, Amazônia, Brasil. Revista Ibero Americana de Ciências Ambientais, v.9, n.7, p.76-89, 2018. DOI:

http://doi.org/10.6008/CBPC2179-6858.2018.007.0008 


\section{INTRODUÇÃO}

Os corpos de água são utilizados de diversas maneiras e fins, como abastecimento de água, irrigação de lavouras, lazer e despejo de águas residuais brutas, sendo a eutrofização artificial uma das principais modificações provocadas pelo homem, geralmente pelo aporte excessivo de nutrientes nos ambientes aquáticos (MARGALEF, 1983).

No Brasil, e na maioria dos países em desenvolvimento, a maior parte do esgoto bruto é lançado sem nenhum tratamento prévio nos cursos de água, esse grande aporte de matéria orgânica e poluentes tem sido relatado como o principal responsável pela eutrofização de uma grande variedade de ambientes aquáticos, gerando preocupação pelo alto nível de poluição e contaminação em que se encontram, atualmente, lagos e outros ambientes aquáticos continentais (TUNDISI, 2003).

A eutrofização é o aumento da concentração de nutrientes, especialmente fósforo e nitrogênio, nos ecossistemas aquáticos, que tem como consequência o aumento de suas produtividades (ESTEVES, 1998). A eutrofização pode ser natural ou artificial, quando natural é um processo lento e contínuo que resulta do aporte de nutrientes trazidos pelas chuvas e pelas águas superficiais que erodem e lavam a superfície terrestre, correspondendo ao que poderia ser chamado de 'envelhecimento natural' do lago (ESTEVES, 1998). A eutrofização artificial pode ser considerada como uma reação em cadeia de causas e efeitos bem evidentes, cuja característica principal é a quebra de estabilidade do ecossistema (homeostasia). A homeostasia em ecossistemas aquáticos caracteriza-se pelo equilíbrio existente entre a produção de matéria orgânica e o seu consumo e decomposição, com o rompimento do estado de equilíbrio, o ecossistema passa a produzir mais matéria orgânica do que é capaz de consumir e decompor. De acordo com Esteves (1998) este desequilíbrio ecológico é acompanhado de profundas mudanças no metabolismo de todo o ecossistema.

O acúmulo de matéria orgânica disponível no ambiente, o faz ser considerado em processo de eutrofização, saindo de sua condição oligotrófica. Essa situação é desencadeada, geralmente quando os fatores limitantes se tornam mais disponíveis nos ecossistemas aquáticos, geralmente quando há uma entrada de maior quantidade de fósforo e nitrogênio, assim podendo-se dizer, que os mesmos são a causa principal da eutrofização.

O principal fator para o processo de eutrofização é a radiação solar, uma vez que é necessária para a fotossíntese de plantas aquáticas. Entretanto, também contribuem para o processo, além da incidência solar, a geografia do entorno do corpo aquático, o grau de penetração da radiação solar na coluna d'água, a magnitude da entrada e o tipo de nutriente e as particularidades de movimento, transporte e dispersão no corpo aquático (BEM, 2009).

Existem numerosos estudos que demonstram haver uma alta correlação entre a distribuição espacial das atividades humanas e o nível de degradação dos recursos hídricos (THORTON, 1990; KIRA et al., 1995; TUFFORD et al., 1998). A eutrofização implica na alteração na qualidade da água para seus diversos fins, fato que justifica a realização dessa pesquisa que tem como objetivo avaliar o índice de estado Trófico (IET) de lagos de águas claras associadas ao baixo Rio Tapajós, estabelecendo as concentrações de fósforo total, 
clorofila-a e IETs nas águas superficiais dos seguinte lagos: Lago Verde, Lago Jacundá, Lago Taparí e Lago Juá, na fase hidrométrica de águas baixas e águas altas.

\section{REVISÃO TEÓRICA}

\section{Estado trófico}

O Índice de Estado Trófico (IET) é uma ferramenta matemática, capaz de classificar o grau de trofia de um corpo hídrico, avaliando a qualidade da água quanto à quantidade de nutrientes e sua relação com crescimento das algas e de macrófitas aquáticas capazes de causar a eutrofização do meio (BEM, 2009; CETESB, 2013).

Para investigar o nível de eutrofização da água, Carlson (1977) desenvolveu um índice que define o estado trófico (IET), segundo a concentração de biomassa, consideradas através das medidas de transparências do disco Secchi, por meio de análise de regressão linear. Utilizando as medidas de transparências contra clorofila-a e fósforo total, que permitam classificar os ecossistemas em categorias, segundo o grau de trofia (Oligotrófico, Mesotrófico, Eutrófico, Hipereutrófico), oferecendo a possibilidade de avaliar a qualidade da água quanto ao enriquecimento de nutrientes e seu efeito relacionado ao crescimento das algas, ou o potencial para crescimento de macrófitas aquáticas (LUNA 2008).

Segundo Tundisi et al. (2011), esses índices funcionam como referências que permitem acompanhar as alterações quantitativas sofridas em virtude das cargas de nutrientes e não apenas isso, envolve outros parâmetros tais como: biomassa fitoplanctônica (Clorofila-a) e concentração de fósforo total aos quais são conferidos valores numéricos que permitem, por meio de uma formula empírica, calcular o índice de estado trófico. Posteriormente Toledo (1983) através de análise estatística por regressão alterou as expressões originais, desenvolvidas por Carlson, (1977) para adequá-las aos ambientes subtropicais.

De acordo com Bem (2009) devido à variação das características dos corpos aquáticos em função do uso e ocupação do solo, houve a necessidade de alterar alguns métodos de avaliação para que estes continuem a representar a realidade. Em função disso, Toledo (1983) alterou o IET inserindo outras categorias de trofia: Ultraoligotrófico, Oligotrófico, Mesotrófico, Eutrófico e Hipereutrófico.

Uma das mais recentes modificações do cálculo de IET para ambientes subtropicais foi realizada por Lamparelli (2004) que utiliza a metodologia de Carlson (1977) e Toledo (1990), porém não considerava na estimativa de estado de trofia, o cálculo de índice de transparência, pois esta variável é afetada pela turbidez decorrente de material em suspensão e não apenas pela densidade de organismos planctônicos segundo Lamparelli (2004).

\section{Fatores determinantes}

A clorofila-a é o pigmento fotossintetizante presente com mais frequência nas populações fitoplanctônicas, por esse motivo é mais utilizada em estudos sobre as condições do ecossistema aquático 
(BASSOI, 2006; MARCIONILIO, 2013). A biomassa fitoplanctônica é determinada a partir da medida da concentração de clorofila-a no ambiente (SANTOS et al., 2010).

O fitoplâncton é composto por cianobactérias e microalgas situadas na zona eufótica da coluna d'água, os organismos do fitoplâncton possuem adaptações para reduzir a velocidade com que afundam isso devido a sua densidade pouco maior que a da água. O fitoplâncton pode ser usado como bioindicador da qualidade da água por responder rapidamente às mudanças ocorridas no meio ambiente de forma natural ou antrópica.

O fósforo $(P)$ é encontrado no ambiente aquático principalmente na forma de ortofosfato (fosfato inorgânico dissolvido), polifosfato e fosfato orgânico, esse elemento está presente na água proveniente de origem natural fazendo parte da composição de rochas, escoado através da água da chuva, partículas atmosféricas e organismos em decomposição e de origem antrópica proveniente de efluentes sanitários e industriais, fertilizantes e partículas de indústrias (ESTEVES, 1998; WETZEL, 1993).

De acordo com Fernandes et al. (2004) o fósforo é um componente importante para o metabolismo dos organismos de água doce e faz parte da membrana celular (fosfolipídios). Pouca quantidade é necessária para os organismos, entretanto o acúmulo de fósforo é favorável ao desenvolvimento de algas, considerado o elemento limitante da produção primária (SANTOS et al., 2010)

\section{Efeitos da eutrofização}

A eutrofização sob muitos aspectos pode ser considerada como uma resposta biológica negativa nos ecossistemas aquáticos (THOMANN et al., 1987). Os efeitos indesejáveis causados são problemas estéticos e recreacionais, grandes variações diurnas na concentração de oxigênio dissolvido podem resultar em concentrações baixas à noite, podendo ocasionar a morte de peixes.

O fitoplâncton e outras plantas criam uma demanda de oxigênio no sedimento de sistemas aquáticos que, por sua vez, resulta em valores baixos de oxigênio dissolvido no hipolímnio de lagos e reservatórios, diatomáceas e algas filamentosas podem bloquear o fluxo de tratamento de filtros e resultar na redução do tempo da retrolavagem, crescimento excessivo de macrófitas aquáticas aderidas que podem interferir na navegação, aeração e capacidade de transporte pelo canal.

\section{MATERIAIS E MÉTODOS}

\section{Localizações das áreas de estudo}

O município de Santarém está localizado na região Oeste do Pará, à margem direita dos rios Amazonas e Tapajós, possui uma área de $24.315 \mathrm{~km}^{2}$, sendo considerado o maior município da região. Apresentando uma população estimada aproximadamente 294.447 mil habitantes (IBGE, 2017). O estudo foi desenvolvido em quatro lagos situados à margem direita do baixo Rio Tapajós, que nasce no estado do Mato Grosso e desagua no rio Amazonas. 
O Tapajós tem origem na confluência dos rios Juruena e Teles Pires, possuindo uma área de drenagem de aproximadamente $764.180 \mathrm{~km}^{2}$ (FEARNSIDE, 2015). Os lagos estudados são geomorfologicamente classificados como lagos de águas claras de terra-firme, de formas redondas ou alongados, na época das chuvas seus regimes fluviais são aumentados e transbordam, com suas águas submergindo parte significativa de suas regiões litorâneas, bem como a vegetação de igapó típicas destes ambientes (ESTEVES, 2011).

Os rios da bacia Amazônica podem ser classificados com relação à coloração de suas águas, Sioli et al. (1962) apresentam uma classificação que diferencia os rios da Amazônia em três tipos distintos: Brancas, Pretas e Claras. Os rios de água clara, como o Tapajós, na bacia do qual os lagos em estudos estão inseridos, apresentam uma baixa quantidade de sedimentos em suspensão e matéria orgânica dissolvida, o que lhes confere um aspecto cristalino, com uma transparência que varia de 1,10 a 4,30 m. quimicamente, as águas claras são mais diversificadas, com pH por exemplo variando de 4,5 a 7,8 (OLIVEIRA et al., 2014).

As características físico-químicas das águas da região em estudo variam amplamente em função da origem da água, do tipo de solo que drenam e das condições climáticas (REBOUÇAS, 2006). Os lagos estudados apresentados na Figura 1, estão submetidos a diversos impactos antrópicos, são caracterizados principalmente por seus usos múltiplos, como praias, navegação, atividade de pesca etc. Todas essas atividades podem contribuir para a degradação da qualidade da água na região.

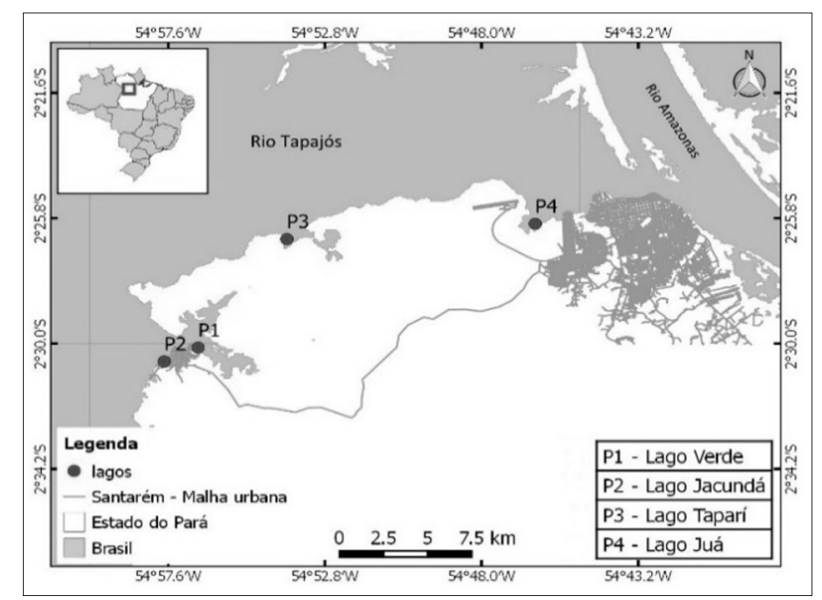

Figura 1: Mapa de localização dos lagos e dos pontos de amostragem da água na cidade de Santarém/PA, Brasil.

\section{Delineamento experimental}

O estudo considerou uma abordagem espacial e temporal, no qual se realizaram duas amostragens em quatro lagos da margem direita do baixo rio Tapajós, sendo uma em outubro de 2016 (período de estiagem) com águas baixas e março de 2017(período chuvoso) com águas altas.

\section{Procedimentos de coleta, transporte e acondicionamento das amostras}

A metodologia para a coleta e conservação das amostras seguiu o protocolo analítico da Normalização Técnica da Companhia de Tecnologia e Saneamento Ambiental do Estado de São Paulo CETESB (1988). As amostras foram coletadas contracorrente na região Limnética, a $20 \mathrm{~cm}$ da superfície e armazenadas em frascos de polietileno de $1.000 \mathrm{~mL}$, conservadas em caixa refrigerada, protegidas contra a 
luz, e transportadas ao Laboratório de Biologia Ambiental (LBA) da Universidade Federal do Oeste do Pará (UFOPA), onde se procedeu a realização das análises. As análises das amostras ocorreram em período inferior a 24 horas para resultado mais confiáveis nas análises laboratoriais.

\section{Análises das amostras}

As análises de fósforo total ( $\left.\mu \mathrm{g} \cdot \mathrm{L}^{-1}\right)$ e clorofila-a $\left(\mu \mathrm{g} \cdot \mathrm{L}^{-1}\right)$ foram determinadas em laboratório, segundo as normas descritas no Standard Methods for the Examinationof Waterand Wastewater (APHA; AWWA; WEF, 2012), onde o princípio do método para fósforo total $\left(\mu \mathrm{g} \cdot \mathrm{L}^{-1}\right)$ consta de uma digestão química da amostra com persulfato, seguida de redução com ácido ascórbico e leitura por espectrofotometria de absorção molecular (Método APHA código 4500-P E). Para clorofila-a utilizou-se o método tricromático, com a extração do pigmento com acetona a 90\%), respectivamente com leitura de extinção de comprimentos de ondas por espectrofotometria de absorção molecular.

\section{Análises estatísticas}

Usaram-se estatística descritiva para verificar os valores médios, máximos e mínimos das variáveis analisadas. Para verificar possíveis diferenças espaciais entre os índices e os períodos de coleta (águas baixas e águas altas), bem como entre os lagos, foram utilizadas análise de variância (ANOVA) entre as variáveis (ZAR, 1984).

\section{Metodologia para obtenção do índice de estado trófico}

O Índice de Estado Trófico foi obtido através da média aritmética entre o Índice de Estado Trófico do Fósforo Total e o Índice de Estado Trófico da Clorofila-a criada por Carlson (1977) e modificado por Lamparelli (2004) para ambientes lênticos subtropicais:

$$
\begin{aligned}
& \text { Clorofila-a }\left(\mu \mathrm{g} \cdot \mathrm{L}^{-1}\right) \quad 10 x(6-((0,92-0,34 x(\ln C L)) / \ln 2)) \\
& \text { Fósforo total }\left(\mu \mathrm{g} \cdot \mathrm{L}^{-1}\right) \quad 10 x(6-(1,77-0,42 x(\ln P T) / \ln 2))
\end{aligned}
$$

Onde: PT: concentração de fósforo total medida a superfície da agua, em $\mu \mathrm{g} \cdot \mathrm{L}^{-1}$. CL: concentração de clorofila a medida a superfície da agua, em $\mu \mathrm{g} \cdot \mathrm{L}^{-1}$. In: logaritmo natural

A faixa de classificação de trofia a partir dos índices de estados tróficos propostos por Lamparelli (2004) estão evidenciadas no quadro 1.

Quadro 1: Especificação da classificação do Índice de estado trófico proposto por Lamparelli (2004).

\begin{tabular}{|c|c|}
\hline Ponderação & Estado Trófico \\
\hline $\mathrm{IET} \leq 47$ & Ultraoligotrófico \\
\hline $47<\mathrm{IET} \leq 52$ & Oligotrófico \\
\hline $52<\mathrm{IET} \leq 59$ & Mesotrófico \\
\hline $59<\mathrm{IET} \leq 63$ & Eutrófico \\
\hline $\mathrm{IET}>67$ & Hipereutrófico \\
\hline
\end{tabular}

O IET médio final obtido para cada lago é a média aritmética simples dos índices relativos ao fósforo total e a clorofila a, segundo a equação:

$$
\text { IET médio }=\text { IET Fósforo + IET Clorofila }-a / 2
$$


Nos tópicos abaixo se observa a especificação da classificação de cada estado trófico proposto por Lamparelli (2004). Ultraoligotrófico: Corpos aquáticos limpos, com produtividade muito baixa e concentrações insignificantes de nutrientes que não acarretam em prejuízos aos usos da água; Oligotrófico: Corpos aquáticos limpos, com baixa produtividade, em que não ocorrem interferências indesejáveis sobre os usos da água decorrentes da presença de nutrientes; Mesotrófico: Corpos aquático com produtividade intermediária, com possíveis implicações sobre a qualidade da água, mas, na maioria dos casos, em níveis aceitáveis; Eutrófico: Corpos aquáticos com alta produtividade em relação às condições naturais, com redução da transparência, em geral afetados por atividades antrópicas, nos quais ocorrem alterações indesejáveis na qualidade da água decorrentes do aumento da concentração de nutrientes interferências nos seus múltiplos usos; Hipereutrófico: Corpos aquáticos afetados significativamente pelas elevadas concentrações de matéria orgânica e nutrientes, com comprometimento acentuado dos seus usos, associado a episódios de florações de algas ou mortandade de peixes, com consequências indesejáveis para seus múltiplos usos, inclusive sobre as atividades pecuárias nas regiões ribeirinhas.

\section{RESULTADOS}

\section{Aspectos Limnológicos Básicos dos Lagos}

A caracterização limnológica básica dos lagos foi realizada considerando os seguintes parâmetros: temperatura, turbidez, condutividade elétrica, oxigênio dissolvido e potencial hidrogeniônico - pH. Os valores absolutos obtidos para os referidos parâmetros por lago e fase hidrométrica de coleta (águas baixas e águas altas) estão apresentados na tabela 1.

Tabela 1: Resultado dos parâmetros físico-químicos referentes aos quatro lagos.

\begin{tabular}{|c|c|c|c|c|c|c|c|c|}
\hline \multirow[t]{2}{*}{ Parâmetros/Lagos } & \multicolumn{2}{|c|}{ Lago verde } & \multicolumn{2}{|c|}{ Lago Jacundá } & \multicolumn{2}{|c|}{ Lago Tapari } & \multicolumn{2}{|c|}{ Lago Juá } \\
\hline & $A B^{1}$ & $\mathrm{AA}^{2}$ & $A B^{1}$ & $A A^{2}$ & $A B^{1}$ & $A A^{2}$ & $A B^{1}$ & $\mathrm{AA}^{2}$ \\
\hline Temperatura $\left({ }^{\circ} \mathrm{c}\right)$ & 30,6 & 30,3 & 30,7 & 30,3 & 30,3 & 30,2 & 30,6 & 31,2 \\
\hline Turbidez (UNT) & 3,11 & 5,62 & 20,9 & 16,0 & 25,2 & 16,3 & 45,4 & 16,0 \\
\hline Condutividade elétrica ( $\mu S / L)$ & 9,0 & 9,21 & 11,5 & 12,5 & 5,3 & 12,2 & 23,3 & 12,3 \\
\hline Oxigênio Dissolvido (mg/L) & 5,3 & 5,5 & 4,8 & 4,2 & 4,4 & 5,3 & 5,2 & 4,4 \\
\hline Potencial Hidrogeniônico-pH & 5,38 & 6,02 & 5,22 & 6,15 & 5,02 & 6,05 & 4,85 & 6,10 \\
\hline
\end{tabular}

$\mathrm{AB}^{1}$ : Águas Baixas; $\mathrm{AA}^{2}$ : Águas Altas.

Os quatro ambientes de estudo são influenciados pelo regime hidrométrico fluvial do rio Tapajós, com duas fases de hidrógrafas extremas (águas altas e águas baixas), com a dinâmica lacustre sendo mais influenciada pela hidrógrafa fluvial de águas altas, que coincide com o período chuvoso da região, o que contribui em distintos padrões temporais dos seus aspectos limnológicos. Os valores absolutos obtidos referidos as concentrações dos parâmetros de Clorofila-a e Fósforo Total, por lago e fase hidrométrica de coleta, estão apresentados na tabela 2.

Os valores mínimos de fósforo total exibidos na Figura 2, coincidiram em três lagos na fase de águas baixas sendo 0,0002 $\mathrm{mg} \mathrm{L}^{-1}$ no lago Verde, Jacundá e Juá, o valor máximo de fósforo total foi de 0,008 $\mu \mathrm{g} \cdot \mathrm{L}^{-1}$ no lago Verde, na fase de águas altas. 
Tabela 2: Valores de Clorofila-a e Fósforo Total dos lagos em estudo.

\begin{tabular}{ccccc}
\hline Fase hidrométrica de coleta & \multicolumn{3}{c}{$\mathbf{A B}^{\mathbf{1}}$} & $\mathbf{A A}^{\mathbf{2}}$ \\
\hline Lago & $\mathrm{CL}\left(\mu \mathrm{gg} \cdot \mathrm{L}^{-1}\right)$ & $\mathrm{PT}\left(\mathrm{mg} \cdot \mathrm{L}^{-1}\right)$ & $\mathrm{CL}\left(\mu \mathrm{g} \cdot \mathrm{L}^{-1}\right)$ & $\mathrm{PT}\left(\mathrm{mg} . \mathrm{L}^{1}\right)$ \\
\hline Lago verde & 5,58 & 0,0002 & 0,62 & 0,008 \\
Lago Jacundá & 4,96 & 0,0002 & 0,01 & 0,0008 \\
Lago Taparí & 1,40 & 0,0003 & 6,20 & 0,0015 \\
Lago Juá & 5,58 & 0,0002 & 2,48 & 0,0007 \\
\hline
\end{tabular}

$\mathrm{AB}^{1}$ : Águas Baixas; $\mathrm{AA}^{2}$ : Águas Altas.

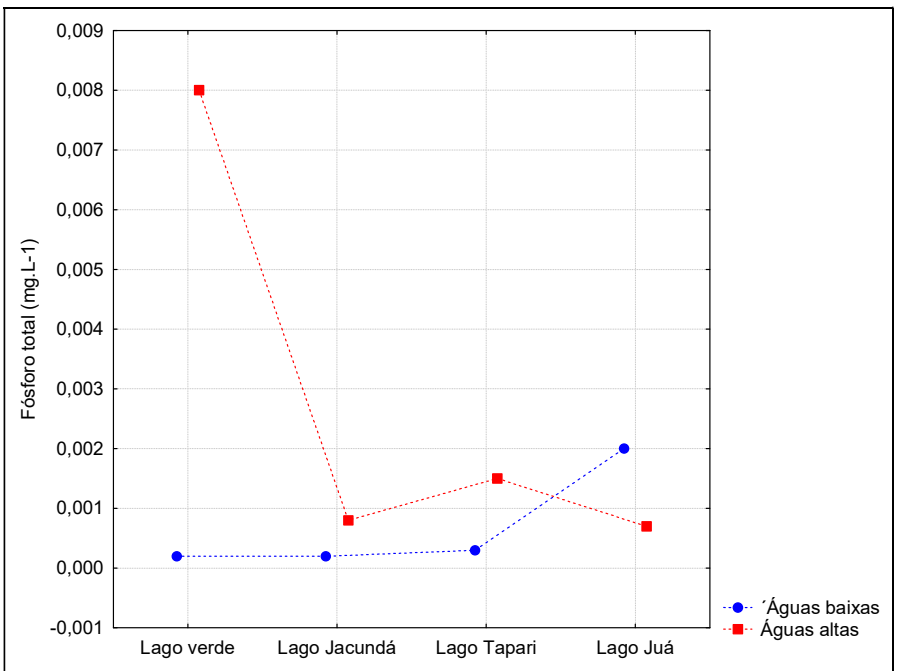

Figura 2: Concentrações de fósforo $\left(\mathrm{mg} \cdot \mathrm{L}^{1}\right)$ total entre lagos e fase hidrométrica de coleta.

As concentrações de fósforo total $\left(F_{(3,4)}=66009 ; p=0,61828\right)$ entre os lagos não apresentaram diferenças significativas, foram levemente mais elevadas na maioria dos lagos no período de águas altas, sugerindo um maior aporte durante a estação chuvosa, porém sem diferença marcante estatisticamente significativa $\left(F_{(1,6)}=1,3088, p=0,29619\right)$. Os valores obtidos de concentrações de clorofila-a são apresentados na figura 3.

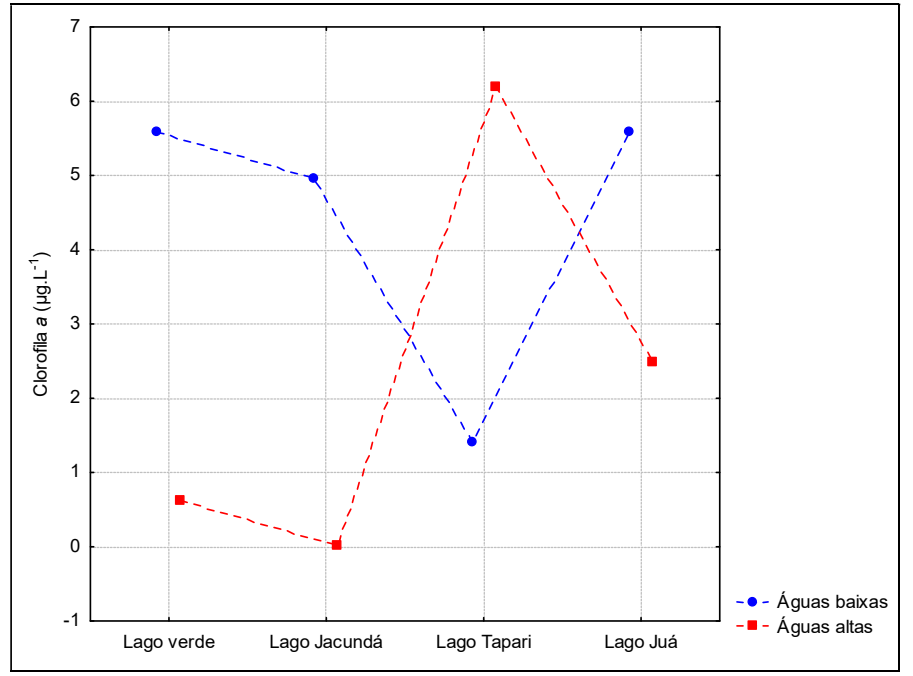

Figura 3: Concentrações de clorofila-a entre lagos e fase hidrométrica de coleta.

Neste estudo os valores máximos das concentrações de clorofila-a foram no período de águas baixas, contudo, quando tratadas isoladamente por lago, os valores máximos de clorofila-a foram apontadas no lago

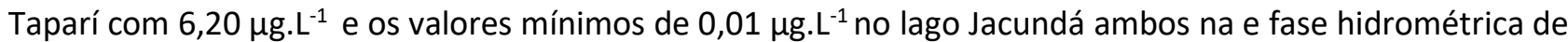
coleta de águas altas. Na estação de águas baixas os valores de $5,58 \mu \mathrm{g} \cdot \mathrm{L}^{-1}$ coincidiram em dois pontos, sendo eles, lago Verde e lago Jacundá, não houve diferenças significativas entre lagos $F_{(3,4)}=, 09667, p=0,95784$. 


\section{Índices de estado tróficos dos lagos}

Os índices de estado tróficos gerados foram classificados de acordo com o nível de trofia proposto por Lamparelli (2004). Os quatro lagos de estudo, apresentaram os valores que se enquadram na classificação Ultraoligotrófico com uma ponderação IET $\leq 47$, conforme a tabela 3.

Tabela 3: Índices de estados tróficos por lago e período de coleta.

\begin{tabular}{|c|c|c|c|}
\hline Lagos & $A B^{1} I E T$ & $A A^{2}$ IET & Estado Trófico \\
\hline Lago Verde & 10,44 & 13,45 & Ultra $^{3}$ \\
\hline Lago Jacundá & 10,15 & 3,32 & Ultra $^{3}$ \\
\hline Lago Taparí & 9,50 & 22,90 & Ultra $^{3}$ \\
\hline Lago Juá & 10,44 & 16,04 & Ultra $^{3}$ \\
\hline Média/desvio padrão & $10 \pm 0,4$ & $14 \pm 8,1$ & \\
\hline
\end{tabular}
$\mathrm{AB}^{1}$ : Águas Baixas, $\mathrm{AA}^{2}$ : Águas Altas, Ultra33: Ultraoligotrófico.

De acordo com Lamparelli (2004) são corpos d'água limpos, de produtividade muito baixa e concentrações insignificantes de nutrientes que não acarretam prejuízos aos usos da água. Os níveis médios de trofia são apresentados na figura 4.

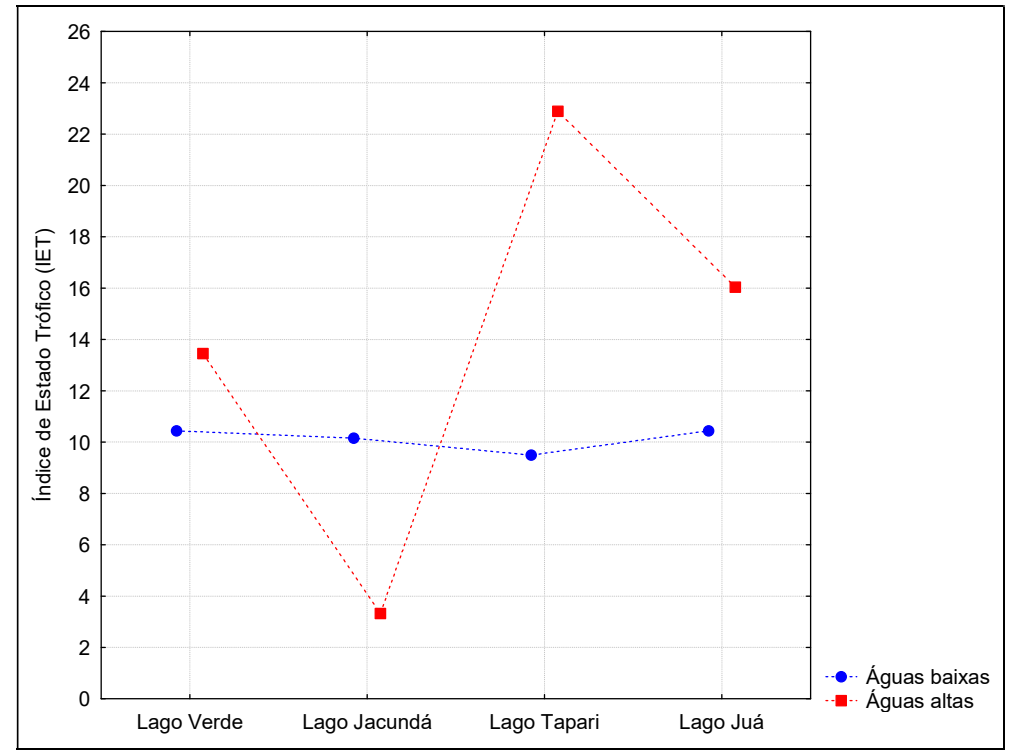

Figura 4: Índices de Estado Tróficos (IETs) ponderados por lago e fase hidrométrica de coleta.

Os níveis de trofia entre os lagos não se diferenciaram significativamente $\left(F_{3,4}=0,93808, p=0,5009\right)$ e, apesar do IET ponderado no período das águas altas ser levemente mais alto $(14 \pm 8,1)$ do que no período de águas baixas $(10 \pm 0,4)$, este contraste não foi estatisticamente significativo.

\section{DISCUSSÃO}

Análise isolada das concentrações de fósforo e clorofila-a frente aos padrões da Resolução 357/ 2005 do CONAMA

A resolução 357/ 2005 do CONAMA dispõe sobre a classificação dos corpos de água e diretrizes ambientais para o seu enquadramento, bem como estabelecer as condições e padrões de lançamentos de efluentes, e dá outras providencias (BRASIL, 2005). Nessa pesquisa os valores de fósforo e clorofila-a, foram enquadrados nos critérios desta Resolução para água doce de classe 2, que podem ser destinadas: Ao 
abastecimento para consumo humano, após tratamento convencional; A proteção das comunidades aquáticas; A recreação de contato primário, tais como natação, esqui aquático e mergulho; $\mathrm{A}$ irrigação de hortaliças, plantas frutíferas e de parques, jardins, campos de esporte e lazer, com as quais o público possa a vir de contato direto; A aquicultura e a atividade de pesca.

Os valores limites estabelecidos nesta resolução definem para clorofila-a o valor até $30 \mu \mathrm{g} \cdot \mathrm{L}^{-1}$; e que as concentrações de fósforo total sejam inferiores a 0,030 $\mu \mathrm{g} \cdot \mathrm{L}^{-1} \mathrm{em}$ ambientes lênticos (BRASIL, 2005). Levando-se em consideração os limites estabelecidos pela Resolução № 357 do CONAMA. Os resultados demonstram que as águas de todo os lagos se encontraram dentro dos limites de conformidade.

Apesar da maioria dos lagos não terem ultrapassado o valor máximo estabelecido pela Resolução CONAMA n³57/2005, que dispõe sobre a classificação dos corpos de água e diretrizes ambientais para o seu enquadramento, Reynolds (2006) afirma que a disponibilidade de fósforo eleva a presença de produtores primários e de biomassa algal, expressa pela clorofila-a. Assim, o aumento dos níveis de fósforo poderá acarretar alterações hídricas, qualitativas e quantitativas, de componentes como pH, oxigênio dissolvido e transparência da água, que poderão comprometer o equilíbrio do ecossistema aquático e causar danos à saúde humana.

Altas concentrações de fósforo em bacias hidrográficas podem ter forte relação com o nível de ocupação urbana. Esgotos domésticos, efluentes liberados por indústrias e uso de fertilizantes em regiões rurais são fatores que ajudam a aumentar os níveis desse nutriente no meio aquático e podem, consequentemente, acelerar o processo de eutrofização das águas (LEAL, 2006), bem como o aumento das formas nitrogenadas em ambiente lênticos. Estudos têm atribuído à duração e intensidade da estação chuvosa, o incremento nas concentrações de fósforo durante o escoamento superficial da água, por influência do aumento no nível de sedimentos em suspensão (QUINTON; CATT; HESS, 2001; JARVIE; NEAL; WITHERS, 2005).

A clorofila-a é uma importante variável nos ecossistemas aquáticos, sendo o principal pigmento responsável pelo processo de fotossíntese. Pode ser considerada como um indicador do estado trófico dos ambientes aquáticos, pois indica a biomassa de algas presente no corpo hídrico (ESTEVES, 1988). Quanto maior penetração de energia radiante no meio aquático, maiores serão as concentrações de clorofila-a.

O aumento das concentrações de clorofila-a é decorrente não apenas das variações na composição e fisiologia das espécies do fitoplâncton, presentes nesses ambientes, mas possivelmente do aumento na biomassa de cianobactérias, as quais passam a ser dominantes nos corpos d'água, o que demonstra possíveis ajustes dessas comunidades fitoplanctônicas às condições ambientais existentes ao longo do tempo (DOMINGOS et al., 2015). De acordo com Boardman (1977) concentrações de clorofila-a tendem a diminuir com a redução da intensidade luminosa Fato evidenciado neste estudo, onde as maiores concentrações de clorofila-a foram no período de águas baixas

No presente trabalho, em todas as amostras foram encontrados valores que indicam consideráveis concentrações de clorofila-a, com um valor médio de $4,8 \mu \mathrm{\mu g} \cdot \mathrm{L}^{-1}$ na e fase hidrométrica de águas baixas e 2,33 $\mu g \cdot L^{-1}$ na estação de águas altas. O que sugere condições ótimas de quantidade de luz, temperatura e 
nutrientes disponíveis de acordo com Minillo (2005). Devido a esses valores médios de concentração de clorofila-a se encontra bem abaixo dos $30 \mu \mathrm{g} \cdot \mathrm{L}^{-1}$ permitidos pelo CONAMA (2005), esses dados são aceitáveis e indicam uma discreta produtividade nos lagos.

\section{Determinação do estado trófico dos lagos de águas claras associados ao Baixo Rio Tapajós}

Segundo Lamparelli (2004), em um corpo hídrico, em que o processo de eutrofização encontra-se plenamente estabelecido, o estado trófico determinado pelo índice da clorofila-a coincidirá com o estado trófico determinado pelo índice do fósforo. Já nos corpos hídricos em que o processo esteja limitado por fatores ambientais, como a temperatura da água ou a baixa transparência, o índice relativo à clorofila-a irá refletir esse fato, classificando o estado trófico em um nível inferior àquele determinado pelo índice do fósforo (MAIA et al., 2015).

O decaimento dos índices de estado tróficos nos lagos no período de águas altas pode estar associado ao aumento da taxa de precipitação, redução da intensidade luminosa e elevação do nível da água dos lagos. Estudos abordando índices de estados tróficos em bacias hidrográficas no Brasil ainda são bastante recentes e bastante rarefeitos por regiões, principalmente na região norte do Brasil.

Na região do baixo rio Tapajós o único trabalho disponível na literatura científica, até o presente, sobre índices de estado tróficos de corpos d'água é o de Aguiar et al. (2014). Este trabalho reportou valores de IETS para 27 microbacias fluviais (igarapés) na região dos municípios de Santarém e Belterra. Os índices de estado trófico relatados foram menores no período chuvoso com IET médio de 47, classificando as águas daqueles igarapés também como Ultraoligotrófico, enquanto no período de estiagem as condições decaíram para oligotróficas com IET médio de 48,14. Para os autores esta variação é influenciada naturalmente pelas áreas totais de captação dinâmica das bacias entre as fases do ciclo hidrológico que envolve a precipitação, infiltração e escoamento. A retirada da cobertura vegetal das áreas de drenagens, em decorrência dos diferentes usos do solo, também potencializa tais alterações.

Maia et al. (2015) reportaram valores de IETs para o baixo rio São José dos Dourados (BSJD), localizado no estado de São Paulo, sendo as águas daquele rio classificadas como sendo ultraoligotróficas $(\mathrm{IET} \leq 47)$ no período chuvoso e oligotróficas $(47<\mathrm{IET} \leq 52)$ no período de estiagem. Estes autores também defendem que o método proposto por Lamparelli (2004) apresentou maior suscetibilidade às mudanças, aumentando, dessa forma, o nível das classificações tróficas; embora o método de Toledo et al. (1983) apresente menores níveis de classificação, a sua variação numérica é maior, sendo capaz de detectar concentrações bem menores.

Para o estado do Paraná, em Curitiba, Bem (2009) reportou valor de IET de 53,75 no Lago Barigui, classificando as águas como mesotróficas, esta categoria está relacionada a corpos aquáticos com produtividade intermediária, o que pode representar possíveis implicações sobre a qualidade da água, embora, na maioria dos casos, em níveis aceitáveis, devido a concentração de algas no sistema.

Índice de estado trófico também tem sido reportado para lagos artificial, como aqueles de reservatórios hidroelétricos ao longo do Brasil. Pereira (2009) reportou valor de IET para a UHE de Marechal 
Mascarenhas de Morais e UHE Luiz Carlos Barreto de Carvalho em Rio Grande, no estado de minas Gerais da ordem de 67, classificando as águas daquelas UHEs como Hipereutróficas. Prado et al. (2007) relataram evolução de IETs entre os anos de 1990 a 2002 no reservatório hidroelétrico de Barra Bonita, no estado de São Paulo. Os valores de IETs variaram de 73,94 a 68,9 do período chuvoso para a estiagem, classificando as águas como hipereutróficas. Por meio das análises dos índices utilizados e da elaboração do mapa de uso e ocupação do solo do entorno do reservatório de Barra Bonita foi possível observar que os tipos de uso do solo empregados em seu entorno, destacando-se as atividades agrícolas, estão contribuindo diretamente para a degradação da água desse ambiente, incrementando a fertilização das águas.

Em estudo realizado por Bem (2009) no Lago Barigui - Curitiba, o cálculo do IET Médio foi 53,75 classificando-o como mesotrófico, esta categoria está relacionada a corpos aquáticos com produtividade intermediária, o que pode representar possíveis implicações sobre a qualidade da água, embora, na maioria dos casos, em níveis aceitáveis, devido a concentração de algas no sistema. Segundo Esteves (1998), até o final da década de 1980, poucos eram os estudos sobre o assunto eutrofização no Brasil. Uma das primeiras pesquisas foi realizada por Cordeiro et al. (1981) no lago Paranoá (Brasília, DF). Nesta pesquisa, os autores, além de identificar as principais fontes de fosfato, realizaram a quantificação do aporte deste elemento em bases anuais para cada uma das fontes identificadas, umas das principais conclusões foram que os efluentes das duas estações de tratamento de esgoto lançados no lago Paranoá são as principais fontes de fosfato antrópicos para este ecossistema e, consequentemente, as maiores responsáveis pela sua eutrofização artificial.

Em muito lagos rasos, a principal consequência da eutrofização artificial é o aumento exagerado das comunidades de macrófitas aquáticas. Em decorrência do crescimento destas comunidades, observa-se rápida redução de profundidade média do lago e a redução da sua qualidade como área de lazer, especialmente banho e esportes náuticos. O método mais eficaz para eliminação das comunidades de macrófitas aquáticas é a sua remoção, que consiste na retirada da biomassa aérea e subterrânea. O lago Hornborga, no sul da Suécia, foi o primeiro a ser restaurado através da retirada de macrófitas aquáticas (ESTEVES, 1998).

\section{CONCLUSÕES}

Os valores ponderados de Fósforo Total e Clorofila-a indicam que atualmente as águas dos Lagos Verde, Jacundá, Taparí e Juá se encontram no estado Ultraoligotrófico; corpos d'água limpos, de produtividade muito baixa e concentrações insignificantes de nutrientes que não acarretam prejuízos aos usos da água. Os valores de IETs médios entre os lagos não se diferenciaram significativamente e, apesar do IET ponderado no período das águas altas ser levemente mais alto do que no período de águas baixas, este contraste não foi estatisticamente significativo.

De acordo com a resolução 357/05, dispõe sobre a classificação dos corpos de água para águas doces de classe 2 as concentrações de Fósforo Total e Clorofila-a se mantiveram dentro da faixa permitida pela 
legislação e do limite recomendado, os lagos apresentaram baixas concentrações de clorofila-a e fósforo total e pouca variação na distribuição destes.

\section{REFERÊNCIAS}

AGUIAR, C. P. O.; PELEJA. J. R. P.; SOUSA, K. N. S. Qualidade da água em microbacias hidrográficas com agricultura nos municípios de Santarém e Belterra, Pará. Revista Árvore, v.38, n.6, p.983-992, 2014.

APHA; AWWA; WEF. Standard Methods for the Examination of Water and Wastewater. $21 \mathrm{ed}$. Washington: American Public and Health Association, American Water Works Association and Water Environmental Federation, 2012.

BASSOI, L. J.. Índices de Comunidades Biológicas para avaliação da qualidade das águas com vistas à preservação da vida aquática. CETESB, 2006.

BARRETO, P. R.; GARCIA, C. A. B.. Caracterização da qualidade da água do açude Buri - Frei Paulo/SE. Scientia Plena, v.6, n.9, 2010.

BEM, C. C.. Determinação do estado de eutrofização de um lago raso: estudo de caso do lago Barigui. Monografia (Especialização em Engenharia de Recursos Hídricos e Ambiental) - Universidade Federal do Paraná, Curitiba, 2009.

BOARDMAN, N. K.. Comparative photosynthesis of sun and shade plants. Annual Review Plant Physiology, v.28, p.355377, 1977.

BRASIL. Ministério do Meio Ambiente. Conselho Nacional do Meio Ambiente (CONAMA). Resolução no 357: Dispõe sobre a classificação dos corpos de água e diretrizes ambientais para o seu enquadramento, bem como estabelece as condições e padrões de lançamento de efluentes, e dá outras providências. Brasília: DOU, 2005.

CARLSON, R. E.. A trophicstate index for lakes. Limnology and Oceanograph, v.22, n.2, p.361-80, 1977.

CETESB. Companhia de Tecnologia de Saneamento Ambiental de São Paulo. Guia de coleta e preservação de amostras de água. São Paulo: CETESB, 1988.

CORDEIRO N. O.; DUTRA, F. D.. O aporte de fósforo ao Lago Paranoá (Brasília). In: CONGRESSO BRASILEIRO DE ENGENHARIA SANITÁRIA E AMBIENTAL, 11. Anais. Fortaleza, Ceará, 1981.

DOMINGOS, A. A.; CARVALHO, S. L.; CARVALHO, F. T.. Comparação de dois índices de determinação do grau de trofia nas águas do Baixo Rio São José dos Dourados, São Paulo, Brasil. Eng. Sanit. Ambient., v.20, n.4, p.613-622, 2015.

ESTEVES, F. A.. Fundamentos de Limnologia. Rio de Janeiro: Interciência, 1998.

ESTEVES, F. A.. Fundamentos de Limnologia. 3 ed. Rio de Janeiro: Interciência, 2011.

FEARNSIDE, P. M. Amazon dams and waterways: Brazil's Tapajós Basin plans. Ambio, v.44, n.5, p.426-439, 2015.
FERNANDES, L.; WOSIAK, A. C.. Comunidades

Fitoplanctônicas em ambientes lênticos. Anhanguera, 2004.

IBGE. Instituto Brasileiro de Geografia e Estatística. Dados sobre o município de Santarém. 2010.

JARVIE, H. P.; NEAL, C.; WITHERS, P. J. A.. Sewage-effluent phosphorus: a greater risk to river eutrophication than agricultural phosphorus?. Science of the Total Environment, v.360, p.246-253, 2005.

KIRA, T.; SAZANAMI, H.. Utilização de recursos hídricos e problemas de gerenciamento de lagos. In: HASHIMOTO, M. Diretrizes para o gerenciamento de lagos. Tóquio, 1995.

LAMPARELLI, M. C.. Grau de trofia em corpos d'água do Estado de São Paulo: avaliação dos métodos de monitoramento. Tese (Doutorado em Ecologia Aplicada) Universidade de São Paulo, São Paulo, 2004.

LEAL, P. R.. Avaliação de indicadores do estado trófico de uma lagoa costeira: lagoa de Jacuném. Monografia (Graduação em Oceanografia) - Universidade Federal do Espírito Santo, Vitória, 2006.

LUNA, B. J. C.. Características espaço-temporais do sistema do Açude Acauã e seu atual índice de estado trófico. Dissertação (Mestrado) - Universidade Federal da Paraíba, 2008.

MAIA, A. A. D.; CARVALHO, S. L.; CARVALHO, F. T.. Comparação de dois índices de determinação do grau de trofia nas águas do Baixo Rio São José dos Dourados, São Paulo, Brasil. Eng. Sanit. Ambient., v.20, n.4, p.613-622, 2015.

MARCIONILIO, S. M. L. O.. Tendências na literatura científica, determinantes locais e regionais da clorofila-a e estado trófico em lagoas de planície de inundação. Goiás: UEG, 2013.

MARGALEF, R.. Limnología. Limnology and Oceanography, v.29, n.6, p.1349-1349, 1983.

MINILLO, A.. Análise da distribuição, densidade e toxicidade de florações de cianobactérias e suas toxinas nos reservatórios do Médio e Baixo Rio Tietê (SP) e relação com as características limnológicas do sistema. Tese (Doutorado em Ciências da Engenharia Ambiental) - Escola de Engenharia de São Carlos, São Carlos, 2005.

OLIVEIRA, L. N.; SILVA, C. E.. Qualidade da água do Rio Poti e suas implicações para atividade de lazer em Teresina-PI. Revista Equador, v.3, n.1, p.128-147.2014.

PRADO, R. B.; MORA, E. M. L.. Avaliação espaço-temporal da relação entre o estado trófico do reservatório de Barra Bonita (SP) e o potencial poluidor de sua bacia hidrográfica. Sociedade \& Natureza, Uberlândia, v.19, n.2, p.5-18, 2007. 
QUINTON, J. N.; CATT, J. A.; HESS, T. M.. The selective removal of phosphorus from soil: Is event size important? Journal of Environmental Quality, Madison, v.30, n.2, p.538545, 2005.

REBOUÇAS, A. C.. Águas subterrâneas. In: REBOUÇAS, A. C.; BRAGA, B.; TUNDISI, J. G.. Águas doces no Brasil: capital ecológico, uso e conservação. Escrituras, 2006.

REYNOLDS, C.. Ecology of phytoplankton. New York: Cambridge University Press, 2006.

SANTOS, D. O.; CARDOSO, R. C.. Avaliação da qualidade da água através do índice de comunidade fitoplanctônica (ICF) e variáveis físico-químicas do Lago Tirolesa. Teresópolis: Anhanguera, 2010.

SIOLI, H.; KLINGE, H.. Solos, tipos de vegetação e águas na Amazônia. Boletim do Museu Paraense Emílio Goeldi. Série avulsa Belém. EMBRAPA, 1962.

THOMANN, R. V.; MUELLER, J. A.. Principles of Surface Water Quality Modeling and Control. Harper Collins Publishers, 1987.
THORTON, W. K.. Perspectives on Reservoir Limnology. In: THORTON, W. K.; PAYNE, F. E.; KIMMEL, B. L.. Reservoir limnology: ecological perspectives. Jonh Wiley and Sons, Inc. 1990.

TOLEDO, J. A. P.; TALARICO, M.; CHINEZ, S. J.; AGUDO, E. G.. A aplicação de modelos simplificados para a avaliação do processo da eutrofização em lagos e reservatórios tropicais. In: CONGRESSO BRASILEIRO DE ENGENHARIA SANITÁRIA E AMBIENTAL. Anais. Santa Catarina: Balneário Camboriú, 1983.

TUFFORD, D. L.; Mc KELLAR JR., H. N.; HUSSEY, J. R.. Stream nonpoint source nutrient prediction with land-use proximity and sasonality. Journal of Environmental Quality, v.27, n.1, 1998.

TUNDISI, J. G.; MATSUMURA-TUNDISI, T.. Recursos Hídricos no Século 21. Oficina de textos. 2011.

TUNDISI, J. G.. Água no século XXI: Enfrentando a escassez. RiMa, IIE. 2003.

WETZEL, R. G.. Limnologia. 2 ed. Lisboa: Fundação Calouste Gulbenkian, 1993.

ZAR, J. H.. Biostatistical Analysis. 2 ed. Prentice Hall, 1984.

A CBPC - Companhia Brasileira de Produção Científica (CNPJ: 11.221.422/0001-03) detém os direitos materiais desta publicação. Os direitos referem-se à publicação do trabalho em qualquer parte do mundo, incluindo os direitos às renovações, expansões e disseminações da contribuição, bem como outros direitos subsidiários. Todos os trabalhos publicados eletronicamente poderão posteriormente ser publicados em coletâneas impressas sob coordenação da Sustenere Publishing, da Companhia Brasileira de Produção Científica e seus parceiros autorizados. Os (as) autores (as) preservam os direitos autorais, mas não têm permissão para a publicação da contribuição em outro meio, impresso ou digital, em português ou em tradução. 